\section{AMSSM thematic issue: care of the female athlete}

\author{
Elizabeth A Joy, ${ }^{1}$ Kelsey Logan ${ }^{2}$
}

\section{INTRODUCTION}

Athletic opportunities for females have come a long way since the passage of Title IX in the USA in 1972, and the first Olympic women's marathon in 1984. More than three million girls participate in highschool sports each year in the USA; there have been consecutive increases in participation in the past 24 years. With a steady rise in participation, come the positives and negatives. The positives range from improved academic performance in school age individuals to enhanced well-being in older athletes, in addition to many other benefits that extend across the lifespan. Negative consequences are inevitable, but are largely preventable. In this issue, several articles highlight the impact of sports and exercise on the health of female athletes.

\section{FEMALE ATHLETE TRIAD AND MORE...}

Dr De Souza and colleagues ${ }^{1}$ review the existing literature and present guidelines on clearance and return to play for athletes affected by the Female Athlete Triad. This document provides the needed guidance to physicians worldwide in caring for those affected by low energy availability, menstrual dysfunction and/or impaired bone health. Dr Goldstick and Dr Constantini ${ }^{2}$ highlight the prevalence of urinary incontinence in active women, noting that it is common, under-reported and undertreated. Between $28 \%$ and $80 \%$ of top female athletes report urinary incontinence. Heightened awareness of this condition, along with implementation of the evaluation and treatment recommendations outlined in the article, would improve the management and likely outcomes. Not surprisingly, pregnancy is a common cause of subsequent urinary incontinence. Dr Morkved and colleagues ${ }^{3}$ provide an excellent review of the

\footnotetext{
'Department of Clinical Outcomes Research, Intermountain Healthcare, Salt Lake City, Utah, USA; ${ }^{2}$ Department of Sports Medicine, Cincinnnati Children's Hospital Medical Center, Cincinnati, Ohio, USA

Correspondence to Dr Elizabeth L Joy, Department of Clinical Outcomes Research, Intermountain Healthcare, 36 S. State St Salt Lake City, UT 84111, USA; liz.joy@imail.org
}

literature on the effect of pelvic floor training during and after pregnancy as a strategy to prevent urinary incontinence.

Pregnancy can also be an opportunity for women to improve their physical activity and fitness level to optimise their health and the health of their developing fetus. The meta-analysis by $\mathrm{Luo}^{4}$ examining physical activity and the risk of gestational diabetes mellitus (GDM) broadens our understanding of the mechanisms by which activity can prevent GDM. Finally, Dr Nicola Brown ${ }^{5}$ addresses mastalgia (breast pain) a little known problem faced by endurance athletes, and how it impacts their participation. Clinicians need to be proactive in assessing this type of breast pain as part of the preparticipation evaluations, and when considering dropout from sport. Exercise-related mastalgia can be prevented. ${ }^{6}$

\section{BURNOUT: AMSSM POSITION STATEMENT}

AMSSM position statements such as that on concussion ${ }^{7}$ carry substantial weight and are widely downloaded and cited. We publish the result of AMSSM's consideration of burnout in youth sport. ${ }^{8}$ Led by AMSSM President Dr John Di Fiori, the statement highlights particular injuries that can make the clinician suspect the 'at-risk' child, ways to make the diagnosis and guidelines for prevention and treatment. The Executive Summary is in the print issue while the rest of the paper is available on the journal's website. Additional substantive material can be found as a web appendix. We will discuss this key issue further via the AMSSM website as well as on the popular BJSM blog (http://blogs.bmj.com/bjsm/).

\section{ANNUAL MEETING: \\ APRIL 5-9 NEW ORLEANS}

As this AMSSM-themed issue goes to press, our attention moves to New Orleans and the 2014 Annual Meeting (April 5-9). This is the largest annual primary care sports medicine focused conference and its reputation for congeniality and networking opportunities is unrivalled. International keynotes include Professors Mark Batt (UK), Peter Fricker (Australia) and Peter
Brukner (Australia/UK). See this link for the programme (http://bit.ly/1bGCXQm). Clinicians can benefit from the premeeting Ultrasound Workshop. Just a few highlights from the programme include 'What does it mean to be a team physician', 'Managing gluteal and hamstring injuries' and 'When disaster strikes-the role of the team physician as a first responder'. The conference programme also includes discussion of the Female Athlete Triad and exercise during pregnancy.

We hope you enjoy this AMSSM-edited thematic issue of BJSM. You can follow The American Medical Society for Sports Medicine on Twitter (@TheAMSSM).Feel free to send ideas for future AMSSM-themed issues to Dr Tyler Wadsworth (ty.wadsworth@sbcglobal.net).

\section{Competing interests None.}

Provenance and peer review Commissioned; internally peer reviewed.

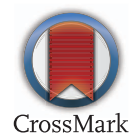

To cite Joy EA, Logan K. Br J Sports Med 2014;48:283.

Accepted 20 December 2013

Br J Sports Med 2014;48:283

doi:10.1136/bjsports-2013-093389

\section{REFERENCES}

1 De Souza MJ, Nattiv A, Joy E, et al. 2014 Female Athlete Triad Coalition Consensus Statement on Treatment and Return to Play of the Female Athlete Triad: 1st International Conference held in San Francisco, California, May 2012 and 2nd International Conference held in Indianapolis, Indiana, May 2013. Br J Sports Med 2014;48:289.

2 Goldstick O, Constantini N. Urinary incontinence in physically active women and female athletes. $\mathrm{Br} J$ Sports Med 2014;48:296-8.

3 Mørkved S, Kari Bø K. Effect of pelvic floor muscle training during pregnancy and after childbirth on prevention and treatment of urinary incontinence: a systematic review. Br J Sports Med 2014;48:299-310.

4 Yin Y, Li X, Tao T, et al. Physical activity during pregnancy and the risk of gestational diabetes mellitus: a systematic review and meta-analysis of randomised controlled trials. Br J Sports Med 2014;48:290-5.

5 Brown N, White J, Brasher A, et al. The experience of breast pain (mastalgia) in female runners of the 2012 London Marathon and its effect on exercise behaviour. Br J Sports Med 2014;48:320-5.

6 Bowles KA, Steele JR, Munro B. What are the breast support choices of Australian women during physical activity? Br J Sports Med 2008;42:670-3.

7 Harmon KG, Drezner JA, Gammons M, et al. American Medical Society for Sports Medicine position statement: concussion in sport. Br J Sports Med 2013:47:15-26

8 DiFiori JP, Benjamin HJ, Brenner J, et al. Overuse injuries and burnout in youth sports: a position statement from the American Medical Society for Sports Medicine. Br J Sports Med 2014;48:287-8. 